\title{
Design, Development, and Implementation of an Open Source Learning Object Repository (OSLOR)
}

\author{
Alex Koohang, Kevin Floyd, Julie Santiago, Steve Greene \\ Macon State College, Macon, Georgia, USA \\ alex.koohang@maconstate.edu; kevin.floyd@maconstate.edu; \\ julie.santiago@maconstate.edu; steve.greene@maconstate.edu
Keith Harman, Oklahoma Baptist University Oklahoma, USA \\ Keith.Harman@okbu.edu
}

\begin{abstract}
This paper presents the birth of an open source learning object repository (OSLOR) from design to implementation. Critical design issues such as user interface, type of LOR, standards, metadata, and the programming language were considered in the process. These issues revolve around the essential characteristics of LOR, i.e., interoperability, reusability, and accessibility. Conclusion and recommendations are made for future advancement of the OSLOR and its sustainability.
\end{abstract}

Keywords: Learning object repository, LOR, open source, OS, OSLOR, LOR design, accessibility, reusability, interoperability, sustainability

\section{Introduction}

Learning Objects (LOs) are assumed to exhibit at least three essential characteristics: 1) accessibility, 2) interoperability, and 3) reusability. Du Plessis \& Koohang (2005) stated that learning objects' accessibility, interoperability, and reusability are interrelated. Accessibility means that the users can easily access learning objects in various platforms. Accessibility is independent of user experience and location. Accessibility depends on interoperability to improve reusability.

Reusability means that a leaning object can be used over and over in various instructional contexts. Learning object reusability can be attained with sound accessibility and interoperability. A set of standards assure the interoperability of LO thus ease their accessibility. Below is a list of

Material published as part of this publication, either on-line or in print, is copyrighted by the Informing Science Institute. Permission to make digital or paper copy of part or all of these works for personal or classroom use is granted without fee provided that the copies are not made or distributed for profit or commercial advantage AND that copies 1) bear this notice in full and 2) give the full citation on the first page. It is permissible to abstract these works so long as credit is given. To copy in all other cases or to republish or to post on a server or to redistribute to lists requires specific permission and payment of a fee. Contact Publisher@InformingScience.org to request redistribution permission. organizations that work on learning objects standards:

- IEEE LO Metadata (LOM) Learning Technology Standards Committee (LTSC)

- Advanced Distributed Learning (ADL) Initiative Shareable Courseware Object Reference Model (SCORM) 
- IMS (Instructional Management System) Global Learning Consortium

- The Dublin Core: Metadata for Electronic Resources

The three essential characteristics, accessibility, interoperability, and reusability meet the needs of learners, instructors, and content developers by providing "chunks" of learning content (i.e. LOs) that may be obtained and used as needed either alone or in combination with other content (c.f. Downes, 2001; Koppi, 2003 as cited in Mohan, 2006; Mohan, 2004, 2006). This is grounded in the practical reality of the convergence of two phenomena: 1) the rise of ubiquitous computing and 2) the emergence of object oriented programming. It is also grounded in the recognition that the lines of demarcation between academic disciplines are becoming increasingly blurred - learning content based in one discipline may often be applicable in or may be foundational to another discipline, e.g. knowledge of mathematics is essential to computer science. Finally, this goal is grounded in the concept that learning is a lifelong pursuit and that a key aspect of lifelong learning is a learner's capacity to become "self-managed," i.e. able to acquire and comprehend content with or without facilitation or direct instruction (c.f. Downes, 2006).

\section{What is a Learning Object?}

Literature has documented various definitions of LO. For example, Downes (2003), Friesen, (2001), and IEEE, (2002) believe that a learning object is either digital or non-digital whereas Wiley (1999) asserted that a learning object is digital in nature.

Harman and Koohang (2005) asserted that "a learning object is not merely a chunk of information packaged to be used in instructional settings. A learning object, therefore, can include anything that has pedagogical value - digital or non-digital such as a case study, a film, a simulation, an audio, a video, an animation, a graphic image, a map, a book, or a discussion board so long as the object can be contextualized by individual learners. The learner must be able to make meaningful connections between the learning object and his/her experiences or knowledge he/she previously mastered. “

For the purposes of this paper we choose to echo the definition of LO by Harman and Koohang (2005) focusing on two points - 1) the LOs are digital, i.e., they are stored in digital form in LOR and 2) they must have educational intent and be easily contextualized by users.

\section{What is a Learning Object Repository?}

For the purpose of this paper, we limit our discussion to digital repositories. A digital repository is "any collection of resources that are accessible via a network without prior knowledge of the structure of the collection." (IMS Global Learning Consortium, 2003).

According to Downes (2002) there are two major forms of LORs - one containing both the learning objects and learning object metadata (the LOR locates and delivers the LOs) and the other consisting of only the learning object metadata (the LOR locates LOs that are placed elsewhere).

Centralized (the most common form of LORs) and distributed are the two major models of LORs. The centralized LOR may contain only the metadata part of the LOs. The actual LOs are located on different servers. The distributed LOR model uses a peer-to-peer architecture that allows multiple servers to communicate with each other. This type of LOR has the metadata in a number of connected servers (Downes, 2002). Below is a list of several LORs:

- Apple Learning Interchange (http://ali.apple.com/ali/resources.shtml)

- Distributed Learning Object Repository Network (DLORN) (http://www.downes.ca/cgibin/dlorn/dlorn.cgi) 
- MERLOT (http://www.merlot.org/Home.po)

- Wisconsin Online Resource Center (http://www.wisc-online.com/)

\section{What is Open Source?}

Koohang and Harman (2005) asserted that open source (OS) is the software's source code made freely available to anyone who wants to expand, adapt, modify, and/or enhance the code. OS software is defined by the GNU project (http://www.gnu.org) as "a matter of the users' freedom to run, copy, distribute, study, change and improve the software." The GNU project states four freedoms regarding the OS software. They are:

- The freedom to run the program, for any purpose (freedom 0 ).

- The freedom to study how the program works, and adapt it to your needs (freedom $1)$. Access to the source code is a precondition for this.

- The freedom to redistribute copies so you can help your neighbor (freedom 2).

- The freedom to improve the program, and release your improvements to the public, so that the whole community benefits (freedom 3 ). Access to the source code is a precondition for this.

Open Source Initiative (http://www.opensource.org), an organization ensuring the integrity of OS software, has proposed a set of principles and values for OS Software. They are as follows:

1. Free redistribution

2. Source code must be included

3. Derived works - allow modifications

4. Integrity of the author's source code

5. No discrimination against persons or groups

6. No discrimination against fields of endeavor

7. Distribution of license

8. License must not be specific to a product

9. License must not restrict other software

10. License must be technology-neutral

Successful examples of OS projects are Linux (http://www.linux.org), Apache (http://www.apache.org), Mozilla (http://www.mozilla.org), and OpenOffice (http://www.openoffice.org) (c.f. Koohang \& Harman, 2005).

Coppola and Neelley (2004) (c.f. Koohang \& Harman, 2005) outlined the following benefits of open source software for open learning.

- The software evolves more rapidly and organically.

- Users' needs are rapidly met as the OSS [Open Source Software] model harnesses their collective expertise and contribution.

- New versions are released very often and rely on the community of users and developers to test it, resulting in superior quality software tested on more platforms, and in more environments than most commercial software. 
- The development "team" is often largely volunteers, distributed, many in numbers, and diverse. Often, paid members of the development team will manage the project and organize the work of the volunteers.

- Security is enhanced because the code is exposed to the world.

In addition the authors assert that OS model encourages collaboration and sharing of resources among the communities of practice.

\section{Learning Objects and Open Source Learning Object Repository}

The "chunks" of learning content (i.e. LOs) have to be stored in a place where they may be identified and retrieved. Otherwise they are of little or no use to those who may want to employ them. Hence there is a need for repositories to store and catalog LOs and that need is met by the Learning Object Repository (LOR).

There are a number of LORs that allow free access to LOs. Examples of these are Apple Learning Interchange (http://ali.apple.com/ali/resources.shtml), MERLOT (http://www.merlot.org/Home.po), and Wisconsin Online Resource Center (http://www.wisconline.com). These are standardized free access repositories. They follow a set of principles created by the organization who owns the repository. They do not reveal the source code to the public.

Alternatively, there are Open Source Learning Object Repositories (OSLORs) where source code is available to the public for use, modification, and/or improvement. These OSLORs may readily meet the unique and special needs of an organization's LOR. There are several OSLORs that are freely available to anyone who wants to expand, adapt, modify, and/or enhance the code. Examples of these are Eduforg (https://eduforge.org/projects/oslor/), MINOR (http://minor.sourceforge.net/), Fedora (http://fedora.info), and dSpace (http://dspace.org).

Perhaps more importantly, OSLORs provide greater opportunities to collect and enhance LOs because there is a greater opportunity to achieve a synergy or virtuous cycle when those involved with repositories are in an optimal position to play dual roles - users can also be producers and enhancers of LO content and vice versa.

The purpose of this paper is to present the birth of an OSLOR from design to implementation. Consistent with its purpose, this paper begins with introductory remarks describing the need for additional OSLORs. A review of literature will consist of the LOR definitions, functions, advantages, opportunities, and challenges. The discussion then shifts to the birth of an OSLOR from design to implementation. Conclusions and recommendations round out the paper.

\section{The Open Source Learning Object Repository}

\section{Design \& Implementation Issue}

Silveira, Omar, and Mustaro (2006) have presented extensive guidance on the design and implementation of LORs. We thus assume that the LOR is a conceptual framework which may be easily coupled with OS concepts.

Research Libraries Group (2002) recommends that an LOR seek to be a "trusted digital repository" in order to assure the reliability of content. Heery (2005) argues that a repository should manage content as well as metadata. Heery (2005) also suggests that a repository should include tools for corporate information management (i.e. tools that allow a set of users to coordinate their 
use of the LOR. Hartwig and Herczes (2003) recommend that objects represent processes as opposed to things.

Silveira et al. (2006) provide extensive guidance as regards centralized versus distributed macrostructures. They also provide guidance on optional storage strategies: file-based, database-based, or persistent objects based.

Hatala, Richards, Eap, and Willms, (2004) as cited in Silveria, et al. (2006) emphasize that interoperability involves design choices relevant to repository services intended to be delivered. Caws and Friesen, (2006) suggest that standards for metadata include reliability of content as well as indexing functionality. Those authors also advocate that repositories focus upon LO context, e.g. handling an LO that is a simulation on queuing problems should differ from the manner in which we handle a slideshow presentation on that same concept.

The design issues we have presented herein offer an important insight - there is no one "best way" to design a LOR. LOR design is critical but the ultimate assessment must focus on the LO accessibility. It is on this essential point that we began to create the OSLOR.

\section{The ISI OSLOR Prototype}

The design of our OSLOR was based on the lack of open source LO repositories. As mentioned earlier, there are several OSLORs available to the LO community. These OSLOR, in our opinion, are complex with little flexibility. They are not easy to implement and may require additional hardware.

In early 2007 we formed a team of 5 volunteer individuals whose skills and experiences included systems design, programming, database design/programming, and user interface design. All individuals in the team were members of the Informing Science Institute (ISI). The ISI advocates knowledge sharing and believes that knowledge should be free to anyone who can benefit from it. All individuals agreed to begin designing and implementing the ISI OSLOR and make the source code available to the LO community as a model to use, expand, adapt, modify, and/or enhance.

The ISI OSLOR is a prototype. It is not the final product. It is the start of an endeavor and our aim is to advance this prototype in hopes of creating a community of practice that will carry on the effort.

Figure 1 shows a screenshot of the ISI OSLOR. The ISI OSLOR contains five categories. They are as follows:

- Arts

- Business

- Humanities

- Mathematics

- Science and Technology

Users can browse through the categories to locate LOs. In addition, users can also use the search capabilities to locate LOs.

The following steps are taken by the LO contributor to share his or her LO to the repository:

1) The contributor creates an account by entering his or her last name; first name; a set of user name and password; his or her organization; and an email account.

2) Once an account is created, the contributor will enter information about the LO he or she is sharing. 
3) The contributor will then reviews and confirms the information before submitting it to the repository. Figure 2 depicts one of the steps for sharing a learning object.

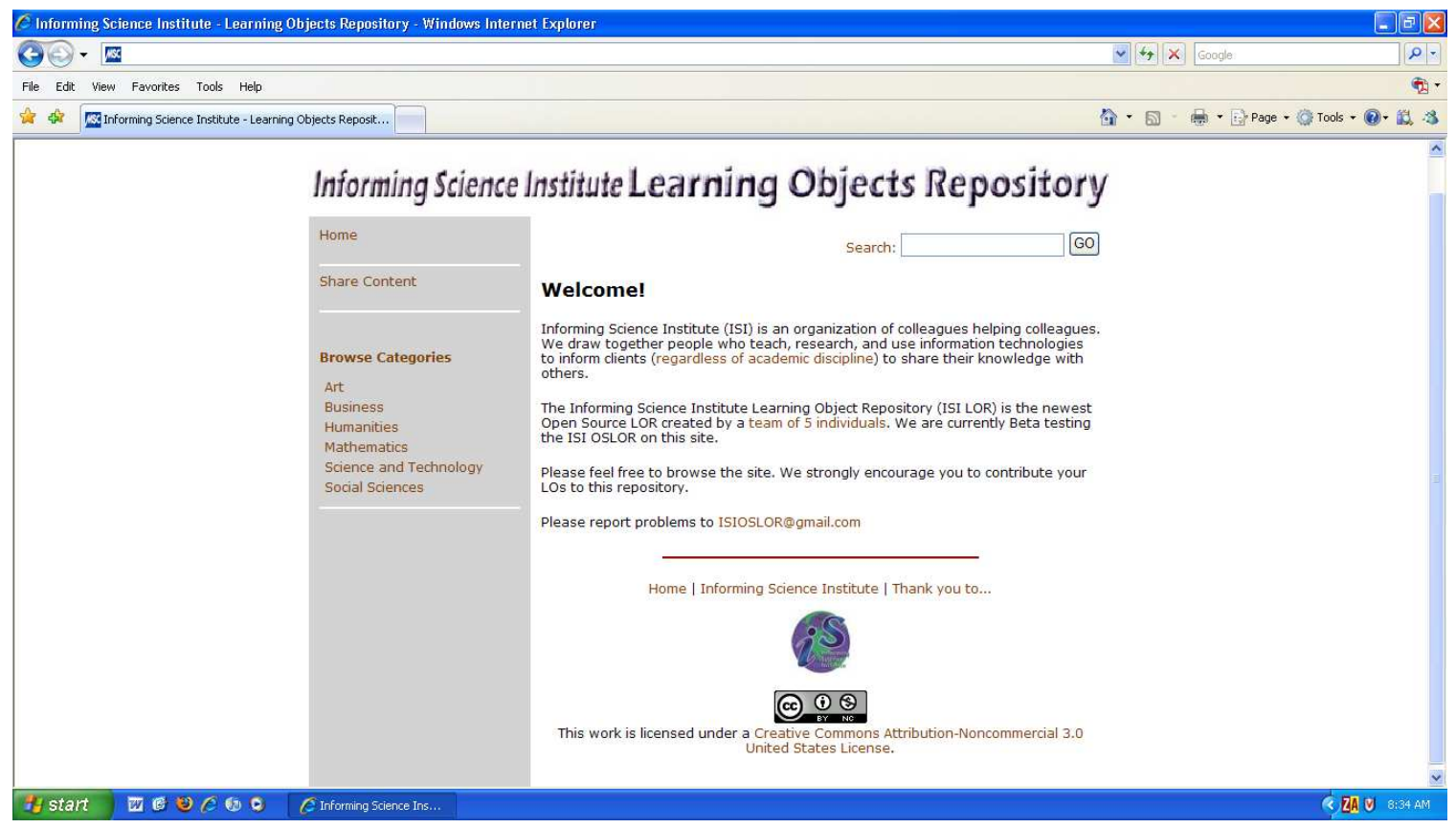

Figure 1: The ISI OSLOR Home page

\section{The Critical Issues in Designing the ISI OSLOR}

The team took into consideration four critical issues in designing and implementing the ISI OSLOR. These issues are as follows:

- The interface design

- The type of LOR

- The programming language

- The metadata and standards

\section{The interface design}

The wide availability of software applications on the Internet has created a highly competitive environment for software designers. User interface design and usability are vitally important in any software design process, but especially in an environment where a user can simply make another choice if an application is poorly designed.

Accurately fulfilling functional specifications produces a software application that functions as designed, with an acceptably low number of errors. However, an application can function perfectly and still be a design failure if user interface design and usability factors are not properly addressed. Usability is the degree to which a software application enables users to effectively and efficiently achieve their goals. It is also integrally associated with the subjective measures of user satisfaction and user acceptance (Nielsen 1993; Rubin, 1994). 


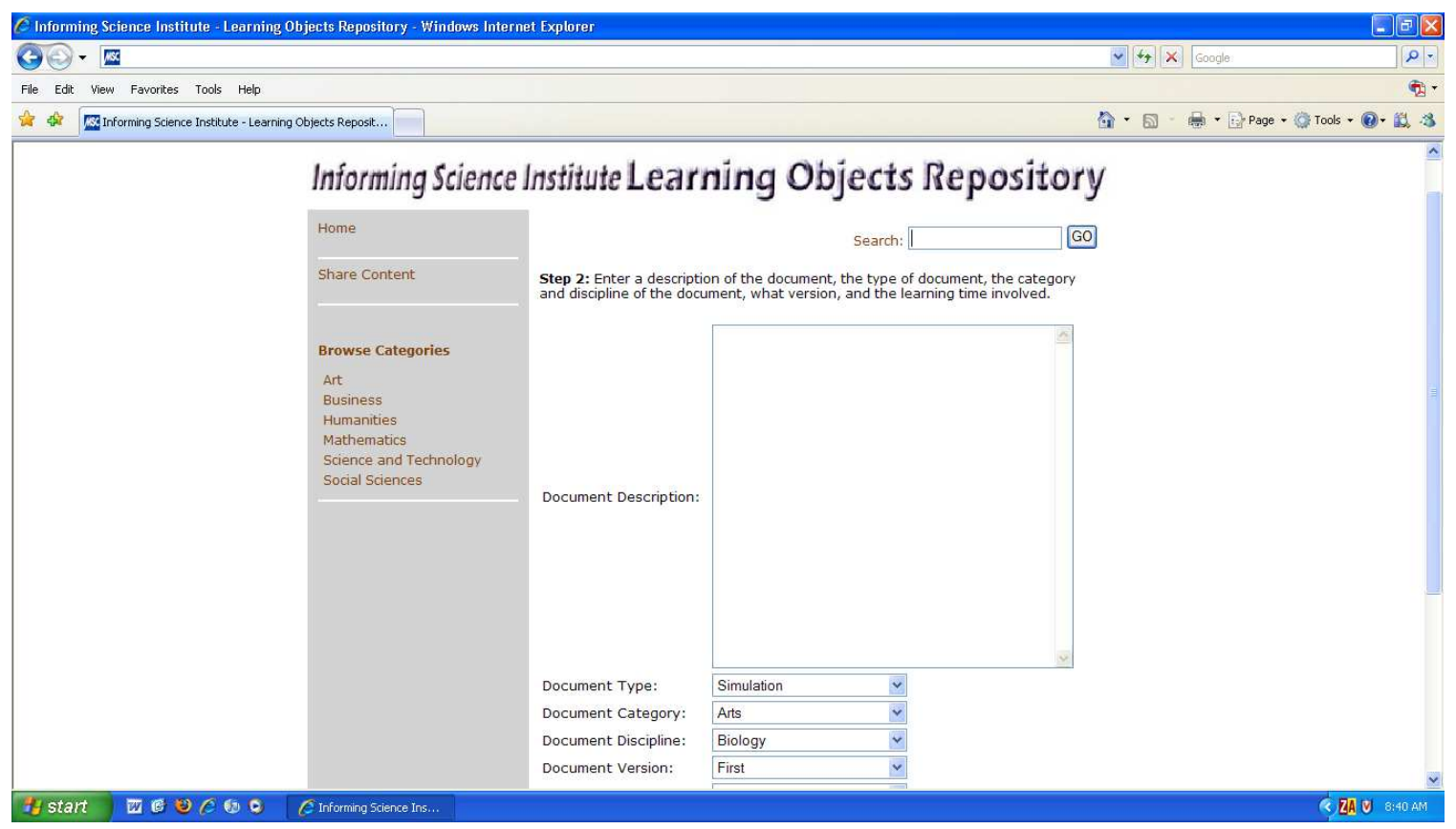

Figure 2: Step two of sharing LO

There are a number of factors that must be considered when designing an application, especially one which will function in a web-based environment.

We chose into consideration the following important user interface design elements (Koohang, 2004a, 2004b):

- $\quad$ Simplicity - The ISI OSLOR must be simple and user-friendly

- Navigability - The ISI OSLOR must be easily navigable.

- Load/Access time - The ISI OSLOR must be loaded/accessed in a reasonable time.

- Readability and Visual Presentation - The ISI OSLOR must be uncluttered and readable.

- Consistency - The ISI OSLOR must include the consistency of terms, words, and actions.

During the design phase of the IS OSLOR, each of the above user interface design/usability element was given meticulous consideration in order to create a simple, scalable and easily navigable interface.

\section{Type of LOR}

We chose to use the centralized model for the ISI OSLOR. However, we provided two options for the LO contributors. Option one includes the link to the LO. The LO contributor only provides the metadata for the LO to be stored in the repository. Option two includes both the LO and the metadata. The contributor uploads the LO into the repository and includes the metadata associated with it.

\section{Metadata \& standards}

As mentioned earlier, a set of standards assure the accessibility and interoperability of learning objects. For the purpose of ISI OSLOR, we follow the IEEE LO Metadata (LOM) Learning Technology Standards Committee (LTSC) P1484. 
"The IEEE Learning Technology Standards Committee (LTSC) is chartered by the IEEE Computer Society Standards Activity Board to develop accredited technical standards, recommended practices, and guides for learning technology. The LTSC coordinates formally and informally with other organizations that produce specifications and standards for similar purposes. Standards development is done in working groups via a combination of face-to-face meetings, teleconferences, and exchanges on discussion groups. The LTSC is governed by a Sponsor Executive Committee (SEC) consisting of working group chairs and elected officers." (http://ltsc.ieee.org/)

The IEEE LOM defines nine categories for learning object metadata. They are as follows:

1. General - Describes the learning object as a whole

2. Lifecycle - The history and current state of learning object

3. Meta-Metadata - Metadata describing the metadata for learning object

4. Technical - Technical requirements and characteristics of learning object

5. Educational - Educational and pedagogic characteristics of learning object

6. Rights - Intellectual property rights and conditions of use for learning object

7. Relation - Relationship with other learning objects

8. Annotation - Comments on the educational use of the learning object

9. Classification - Learning object's relation to a particular classification system

The ISI OSLOR prototype uses the above IEEE LOM categories. It is noteworthy to mention that there are a total of 76 data elements in the LOM in which we chose only a handful for the ISI OSLOR prototype. Friesen (2005) asserted that the support of all 76 LOM elements and their complex data structures are extremely difficult to implement using the current database technologies.

\section{Programming language}

The programming language choice for the ISI OSLOR was the open source PHP. PHP runs on virtually any platform and is appropriate for Web programming. It can be embedded into XHTML. Speed, stability, security, and simplicity are all attributes of the PHP language (Pushman, 2000).

The ISI OSLOR pages are written completely in XHTML 1.1. They conform to XHTML 1.1 standards. They meet all W3C CSS standards and all 3 priority levels of the W3C accessibility guidelines. The layout is pure CSS with no tables or other elements that can cause accessibility problems.

It is noteworthy to mention that the database design and programming required a great deal of attention to normalization. The process of normalization for a database is to ensure the proper interaction, representation, and results of data from the database to obtain the pertinent information required by an organization. The ISI LOR was originally one table thus representing one entity. The single table contained all contributor's data and file data needed to represent the LO to be uploaded. Within this single table, two entities were identified; contributor and file. The single file was then normalized to represent these two tables. The tables of contributor and file are joined by the primary key in the contributor table to the referential foreign key in the file table. The data structure provided will reduce data redundancy as well as provide security. Each contributor will have an ID and a password to access the repository. Uniqueness was ensured throughout this process. 


\section{Implementation and Testing}

The ISI OSLOR is implemented on the Informing Science Learning Object Repository (ISLOR) site (the site is not yet available to public). It is currently being tested by the ISI OSLOR team to point the initial bugs. The ISLOR will be available to public for the beta testing in early 2008. The ISLOR source code will be available for free download in summer 2008.

\section{Conclusion}

This paper described the birth of the Informing Science Institute Open Source Learning Object Repository (ISI OSLOR) from design to implementation. It began by discussing the need for OS LOR and its importance for the LO community. Four critical issues that influence the accessibility, interoperability, and reusability of the LOs were discussed in relation to the design of the ISI OSLOR. The critical issues were 1) the interface design, 2) the type of LOR, 3) the programming language, and 4) the standards.

We believe that the ISI OSLOR, like any other OSLOR, requires further development and continuous improvement. The development and continuous improvement of the ISI OSLOR, however, must address the issue of sustainability. Many of the challenges and opportunities posed by Open Educational Resources (OERs) are mirrored in the development and continuous improvement of OSLORs. Sustainability of OERs is based upon their:

- Design and presentation

- Production and maintenance

- Emergence of communities of practice (Koohang \& Harman, 2007).

OSLORs' sustainability will be based primarily upon those three factors. Developing communities of practice is the most critical sustainability issue. We would argue that the "spirit" of OS assumes that communities of practice are primarily voluntary in nature. Interestingly, Wenger (1998) argues that communities of practice have a mutual engagement and shared resources - a synergy that would characterize a sustainable LOR be it OS-based or not. We would suggest, however; that the synergy is more likely to be optimized in an OS-based model and thus more likely to be sustainable.

If OS is treated as a philosophy as much as it is treated as an issue of intellectual property then LOR design will have one constant: accessibility by users and producers/developers who can morph from one role to the other. In an age of self-managed teams we would propose that OSLOR provides a viable means of minimizing the maintenance and maximizing the sustainability of LORs.

With the help of the LO community of practice, we hope to include collaborative mechanisms for the IS OSLOR that are asynchronous and/or synchronous in nature. For example OSLORs should feature an IRC (Internet Relay Connection) feature, i.e. a chat function. In addition we would recommend that blogs, bulletin boards, and discussion boards would offer users and developers greater opportunities for collaboration and more importantly a space where communities of developers and users could coalesce. Admittedly, one could simply email a content author or contributor and they could use existing IRC tools, e.g. MSN Instant Messenger ${ }^{\mathrm{TM}}$ and bulletin boards to collaborate. However we would suggest that having those features as a part of an OSLOR's repertoire will encourage users and developers to identify the OSLOR as a "place" as opposed to merely a repository. We would further argue that this is an important mental shift that needs to occur if LORs (OS-based or not) are to live up to and hopefully exceed their promise. 


\section{References}

Berners-Lee, T., Hendler, J., \& Lassila, O. (2001). The Semantic Web. Scientific American, 284(5), 34-43.

Caws, C., Friesen, N., \& Beaudoi, M. (2006). A new learning object repository for language learning: Methods \& possible outcome. Interdisciplinary Journal of Knowledge and Learning Objects, 2, 111124. Retrieved from http://ijello.org/Volume2/v2p111-124Caws.pdf

Coppola, C., \& Neelley, E. (2004). Open source open learning: Why open source makes sense for education. Retrieved November 01, 2007, from http://www.rsmart.com/assets/OpenSourceOpensLearningJuly2004.pdf

Downes, S. (2001). Learning objects: Resources for distance education worldwide. International Review of Research in Open and Distance Learning, 2(1).

Downes, S. (2002). Design and reusability of learning objects in an academic context: A new economy of education? USDLA Journal, 7(1). Retrieved November 1, 2007 from http://www.usdla.org/html/journal/JAN03_Issue/article01.html

Downes, S. (2003). Designing learning objects. Retrieved October 4, 2007 from http://www.ibritt.com/resources/dc_objects.htm

Downes, S. (2006). Learning networks and connective knowledge. Retrieved October 18, 2007 from http://it.coe.uga.edu/itforum/paper92/paper92.html

Du Plessis, J., \& Koohang, A. (2005). Learning object: From conceptualization to utilization. Proceedings of Knowledge Acquisition and Management Conference, 13, 38-46.

Friesen, N. (2001). What are educational objects? Interactive Learning Environments, 9(3), 219-230.

Friesen, N. (2005). Interoperability and learning objects: An overview of e-learning standardization. Interdisciplinary Journal of Knowledge and Learning Objects, 1, 23-31. Retrieved from http://ijello.org/Volume1/v1p023-031Friesen.pdf

Harman, K., \& Koohang A. (2005). Discussion board: A learning object. Interdisciplinary Journal of Knowledge \& Learning Object, 1, 67-77. Retrieved from http://ijello.org/Volume1/v1p067077Harman.pdf

Hartwig, R., \& Herczeg, M. (2003). A process repository for the development of e-learning applications. Proceedings of 3rd IEEE Intl. Conf. on Advanced Learning Technologies. Athens, Greece, July.

Hatala, M.; Richards, G.; Eap, T., \& Willms, J. (2004). The interoperability of learning object repositories and services: Standards, implementations and lessons learned. Proceedings of the 13th International World Wide Web Conference on Alternate Track Papers \& Posters. New York, May.

Heery, R. (2005) Digital repositories review. Retrieved October 18, 2007 from http://www.jisc.ac.uk/uploaded_documents/rep-review-final-20050220.pdf

IEEE. (2002). IEEE Standard for Learning Object Metadata. 1484.12.1-2002.

IMS Global Learning Consortium. (2003). The IMS digital repositories specification. Retrieved October 18, 2007 from http://www.imsglobal.org/digitalrepositories/

Koohang, A. \& Harman, K. (2005). Open source: A metaphor for e-learning. Informing Science Journal, 8, 75-86. Retrieved from http://inform.nu/Articles/Vol8/v8p075-086Kooh.pdf

Koohang, A. \& Harman, K. (2007). Advancing sustainability of open educational resources. Issues in Informing Science and Information Technology, 4. Retrieved October 18, 2007 from http://iisit.org/IssuesVol4v2.htm

Koohang, A. (2004a). Expanding the concept of usability. Informing Science Journal, 7, 129-141. Retrieved from http://inform.nu/Articles/Vol7/v7p129-141-002.pdf 
Koohang, A. (2004b). Development and validation of an instrument for assessing users' views about the usability of digital libraries. Issues in Informing Science \& Information Technology, 1, 55-63. Retrieved from http://proceedings.informingscience.org/InSITE2004/018kooha.pdf

Koppi, T. (2003). Institutional use of learning objects three years on: Lessons learned and future directions. Learning Objects Symposium, Honolulu, Hawaii, USA, June 24.

Mohan, P. (2004). Design issues for building reusable digital learning resources. International Conference on Education and Information Systems: Technologies and Applications, Orlando, Florida, USA, July 21-25, 2004, 171-176.

Mohan, P. (2006). Learning object repositories. In A. Koohang \& K. Harman (Eds.) Learning objects: Theory, praxis, issues, and trends (pp.531-54). Santa Rosa, California: Informing Science Press.

Nielsen, J (1993). Usability Engineering. San Diego, CA: Academic Press

Pushman, J. (2000). Why PHP? Web developers journal. Retrieved October 4, 2007 from http://www.webdevelopersjournal.com/articles/why_php.html

Research Libraries Group. (2002). Trusted digital repositories: Attributes and responsibilities. Retrieved October 18, 2007 from http://www.rlg.org/longterm/repositories.pdf

Rubin, J. (1994). Handbook of usability testing: How to plan, design, and conduct effective tests. New York, NY: John Wiley \& Sons.

Silveira, I., Omar, N; \& Mustaro, P. (2006). Architecture of learning objects repositories. In A. Koohang \& K. Harman (Eds.), Learning objects: Theory, praxis, issues, and trends (pp.131-155). Santa Rosa, California: Informing Science Press.

Wenger, E. (1998). Communities of practice: Learning as a social system. Retrieved October 18, 2007 from http://www.co-i-1.com/coil/knowledge-garden/cop/lss.shtml

Wiley, D. (1999). The Post-LEGO learning object. Retrieved October 4, 2007 from http://wiley.ed.usu.edu/docs/post-lego/

\section{Biographies}

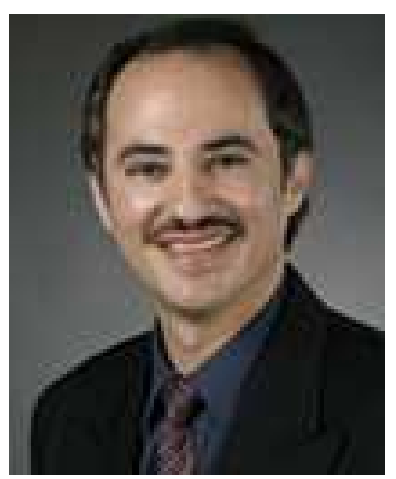

Alex Koohang is professor of Information Technology and Dean of the School of Information Technology at Macon State College. Dr. Koohang has been involved in the development of online education, having initiated and administered some of the earliest asynchronous learning networks. His current research interests are in the areas of e-learning, learning objects, open education, open access, open source, and knowledge management. 


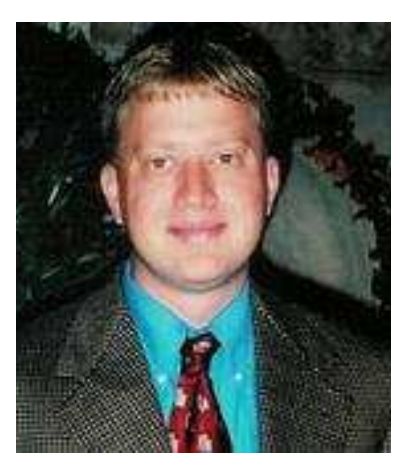

Kevin Floyd is assistant professor of Information Technology in the School of Information Technology at Macon State College. He teaches in the areas of programming \& application development, information security, and IT integration. His current research interests are in the areas of open source, accessibility, and information security.

Julie Santiago is assistant professor of Information Technology in the School of Information Technology at Macon State College. She teaches in the areas of programming \& application development, information security, and IT integration. Her current research interests are in the areas of accessibility and IT integration.

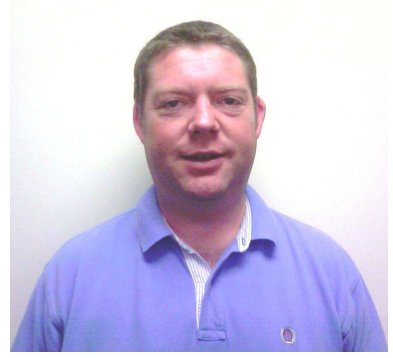

Steve Greene is assistant professor of Information Technology in the School of Information Technology at Macon State College. He teaches in the areas of database, database administration, and database security. His current research interests are in the areas of databases and information security.

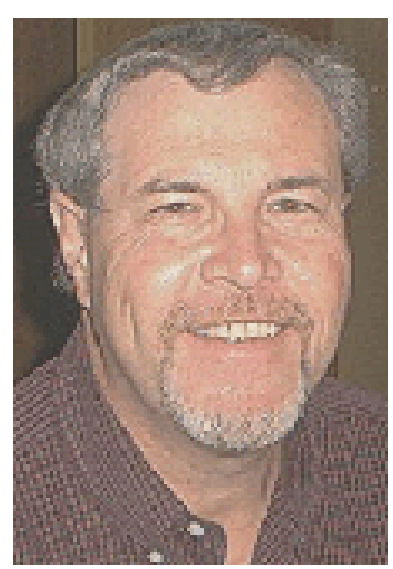

Keith Harman is professor of Business at Oklahoma Baptist University. Dr. Harman's 25 years of experience in academe include stints as a faculty member, department chairperson, dean, and academic research administrator. In addition to three books on information management and strategic planning and over two dozen publications and presentations in journals and proceedings, he has served as a guest lecturer and consultant for Fortune 1000 corporations, major universities, private foundations and government agencies. 